\title{
In vitro evaluation of immunogenic properties of active dressings
}

\author{
Joanna Orlowska ${ }^{1,3 \star}$, Urszula Kurczewska ${ }^{2}$, Katarzyna Derwinska $^{3}$, \\ Wojciech Orlowski ${ }^{3}$, Daria OrszUlak-Michalak ${ }^{2}$
}

${ }^{1}$ Ph.D. Student, Medical University of Lodz, Pl. Hallera 1, 90-647 Lodz, Poland

${ }^{2}$ Department of Biopharmaceutics, Medical University of Lodz, Muszynskiego 1, 90-153 Lodz, Poland

${ }^{3}$ Science and Research Laboratory Dermin Sp. z o.o., Milionowa 23, 93-193 Lodz, Poland

\section{ARTICLE INFO \\ Received 20 February 2014 \\ Accepted 10 March 2014}

Keywords:

dressings,

immune response,

inflammation.

\begin{abstract}
The aim of this study was in vitro evaluation of the level of the immune response in relation to wound dressings composed of alginate, calcium carboxymethylcellulose, and dibutyrylochitin and determination of the direction of response, which will make referring next to the results of in vivo phase possible.

The subject of the experiments was to examine the commercially available, biodegradable alginate dressing, commercially available but not biodegradable dressing constructed from the sodium carboxymethylcellulose, and synthesized in house biodegradable dressing constructed of the dibutyrylchitin. To determine the direction of the immune response, the degree of secretion of pro-inflammatory interleukin (IL-1, IL-6) and antiinflammatory (IL-10) interleukin from murine fibroblasts having contact with the tested dressings (ELISA enzyme linked immunosorbent assay), was tested.
\end{abstract}

\section{INTRODUCTION}

The sixties of the twentieth century brought a new concept in the treatment of wounds in a humid environment, proposed by Winter in 1962 [32]. Trials conducted for years have shown that moist environment present in wound bed accelerates healing and maintains the optimal $\mathrm{pH}$. Moist wound exudates contain growth factors such as Platelet-derived Growth Factor (PDGF), Vascular Endothelial Growth Factor (VEGF), Transforming Growth Factor- $\alpha$ (TGF- $\alpha$ ), Transforming Growth Factor- $\beta$ (TGF- $\beta$ ) and a number of other cytokines including interleukins: IL-1 [28], IL-6 [9], IL-10 [7] that regulate the granulation, epithelialization and angiogenesis during the healing process $[4,12]$.

The process of wound healing can be divided into three major phases: inflammation, proliferation of cells, and the newly formed tissue remodeling. Physiologically extending inflammation is necessary for correct wound healing. Whereas inhibition of inflammatory process leads to the pathology in further stages of wound healing.

Applied dressings play the role of the temporary extracellular matrix (ECM) in the injured tissue.

The extracellular matrix is a very dynamic structure, being a huge reservoir of collagenous and non-collagenous

\footnotetext{
Corresponding author

* e-mail: joanna.orlowska @ dermin.pl
}

proteins immersed in the aqueous polysaccharide gel, allowing the contact between the cells.

One of the major non-collagenous proteins included in the ECM is fibronectin. This large adhesive glycoprotein is produced by fibroblasts. Fibronectin is essential for cell-cell and cell-extracellular matrix interactions.

Fibronectin is involved in the processes of repair of tissue during healing and plays a crucial role during cell migration and angiogenesis [17].

Although the application of the dressing is implantation of a foreign body into the wound bed, it should not cause strong secondary inflammatory response; it should not completely suppress the inflammatory process either, but the contact of the dressing with the wound tissue may change the primary immune reaction [18].

Currently used dressings providing an optimum humidity are called active dressings. They are often characterized by additional properties accelerating cell proliferation. The antimicrobial activity of active dressing enrichment is achieved by addition of silver salts, antibiotics or other substances having similar effect such as polyhexamethylene biguanide (PHMB) [6].

Dressings applied to the skin and mucous membranes must meet a number of requirements related to the safety of their use like biocompatibility, lack of toxicity, and relevant physico-chemical properties [23,29].

Polymers used for dressing design can be divided with regard to the origin of the material used for their production. 
Polymers of natural origin (alginates, chitin, chitosan, collagen) are currently the main object of scientific interests because of their properties such as biocompatibility, biodegradability, ease of acquisition, and relatively low processing costs.

Calcium alginate is a polymer having the polysaccharide structure composed of residues of $\alpha$-L-guluronic $(G)$ and $\beta$-D-mannuronic (M) acids [10], obtained from brown algae (Phaeophyceae), or produced by bacteria Azotobacter vinelandii, Peudomonas fluorescent, Pseudomonas aeruginosa.

This is a common and easy to handle biocompatible polymer, in the context of the pharmaceutical application.

Under the influence of the exchange of calcium ion, associated with subunits of guluronic acid on sodium ion derived from wound exudate, dressing takes the form of a gel by binding excess exudate around the fibers of the dressing. The remains of the polymer in the wound are biodegradable and do not cause wound irritation $[5,13]$. Moreover, a dressing constructed from calcium alginate has a hemostatic effect associated with the presence of calcium ions in its structure [13]. Alginic acid derivatives are easy to handle, biodegradable materials for producing biocompatible dressings, implants and scaffolds for cells $[10,11,20,31,33]$.

In the course of experiments, we also used the tested dressing made of carboxymethylcellulose, which is a polymer known to fix exudate within its fibres, unlike to alginate dressing retaining the pleural around the fibers. The dressing in contact with the discharge is converted into a transparent gel, which fills the wound. The tested dressing is made in accordance with Hydrofiber ${ }^{\circledR}$ technology that enables vertical absorption of exudate. The use of the dressing prevents maceration of the wound edges, making its changes virtually painless for the patient [25]. Carboxymethylcellulose is not a biodegradable polymer. Bandages, after the evaporation of fluid from the surface of wound, take the form of "plaster cast" and fall of from wound bed without damaging it.

Another tested dressing is composed of an ester derivative of chitin - dibutyrylchitin (DBC). Chitin itself is an extremely interesting polymer for designing the bioactive dressings, however, its low solubility limits its use [24]. Dibutyrylochitin is obtained by semi-synthesis. It is characterized by good solubility in most organic solvents such as DMSO, ethanol or acetone. It has also antibacterial, antifungal, and high biocompatibility properties [14,21]. Easy production process allows for using it as raw material for manufacturing adhesive dressings and implants. Chitin and its derivatives are characterized by low cytotoxicity and hemostatic properties [14-16, 19, 22, 26, 27].

Technical University of Lodz has developed original method for the synthesis of ester derivative of chitin (DBC). Dibutyrylochitin polymer is easy to process, is soluble in most organic solvents, thus allowing the formation of films and fibers [27].

In the present work the dressing materials composed of calcium alginate, sodium carboxymethylcellulose and dibutyrylchitin were tested.
The aim of the study was an in vitro evaluation of the level of the immune response in relation to the chosen polymer and the effect of the fibronectin presence that will further be referred to in vivo phase.

In this study, we examined the commercially available, biodegradable alginate dressing, commercially available but not biodegradable dressing constructed from the sodium carboxymethylcellulose, and commercially unobtainable biodegradable dressing made of a dibutyrylchitin. For determining the direction of the immune response, the assessment of the degree of secretion of interleukin being proinflammatory (IL-1, IL-6) and anti-inflammatory (IL-10) from murine fibroblasts that are in contact with the tested dressings, the ELISA tests were used (ELISA enzyme linked immunosorbent assay). The effect of fibronectin addition was also tested.

\section{MATERIAL}

- Dressing constructed from calcium alginate - Sorbalgon ( $)$ producer: Paul Hartmann AG, Heidenheim Germany, no. series: 200337111, expiry date 09.2017

- Dressing made with sodium salt of carboxymethyl-cellulose - Aquacel ${ }^{\circledR}$ producer: ConvaTec, Inc., Skillman NJ USA, no. series: 2H02624, expiry date 08.2017

- dibutyrylochitin (sample nr.13IPS, the degree of esterification $>98 \%$ )

Dibutyrylochitin polymer was purchased at the Institute of Leather Industry in Lodz in the Department of Experimental Application. Dibutyrylochitin was synthesized by methanesulphonic method.

The purchased $3 \%$ polymer solution $(\mathrm{w} / \mathrm{v})$ was prepared in $95.6 \%$ ethanol and poured on a Petri dish. After the initial evaporation of ethanol, the $\mathrm{NaCl}$ crystals were applied to the surface of polymer and dried at $37^{\circ} \mathrm{C}$ for 48 hours. $\mathrm{NaCl}$ crystals were next rinsed with the PBS. Prepared films were than sterilized by autoclaving $\left(121^{\circ} \mathrm{C}, 15 \mathrm{~min}\right)$ and used as a material for further research.

Murine ELISA immunoassays (Diaclone ® Elisa Kit):

- IL-1, no. Series: 87172019, 09.2014

- IL-6, no. Series: 2006-20, 08.2014

- IL-10, no. Series: 2010-19, 08. 2014

Cell cultures: Commercially avaliable murine fibroblast cell line from ATCC® CCL-163 (Balb /c 3T3, Mus musculus, embryo) was used in the experiment.

\section{Equipment: ADAM - MC NanoEnTec}

Reagents: DMEM (Dulbecco's Modified Eagle's Medium), ATCC $\AA$, FCS (FetalCalf Serum), ATCC®, P/S (Solution of penicillin/streptomycyn), ATCC $®$, PBS (Phosphate buffered saline), Gibco ${ }$, Fibronectin, Sigma-Aldrich $\AA$, Ethanol 96\%, Erochem BGD sp. z o.o., Sodium chloride,

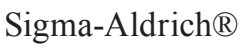




\section{METHODS}

Inoculation of the mouse fibroblast $\mathrm{Balb} / 3 \mathrm{t} 3$ on the tested dressings:

Tested polymers were loaded with commercial cell line Balb/3T3. The cells were previously counted using a device to the amount of cells ADAM NanoEntec ${ }^{\circledR}$ (number of cells $3.6 \times 10^{5} / \mathrm{ml}$ ).

Test patches of dressings $1 \mathrm{~cm} \times 1 \mathrm{~cm}$ were placed in 6 well plates.

For each of the tested materials mouse line fibroblasts were seeded (counted before using the camera). Additionally the effect of fibronectin (a protein secreted by fibroblasts) at the extent of cytokine secretion was studied. For this purpose, 6-well plate was coated with fibronectin $(10 \mathrm{uL}$ fibronectin/1 ml PBS).

Cells were seeded in the system:

F-control

$\mathrm{F}+\mathrm{FN}-\mathrm{control}$

$\mathrm{F}+\mathrm{ALG}$

$\mathrm{F}+\mathrm{CMC}$

$\mathrm{F}+\mathrm{DBC}$

$\mathrm{F}+\mathrm{FN}+\mathrm{ALG}$

$\mathrm{F}+\mathrm{FN}+\mathrm{CMC}$

$\mathrm{F}+\mathrm{FN}+\mathrm{DBC}$

F - fibroblasts, FN - fibronectin, ALG - dressing constructed from calcium

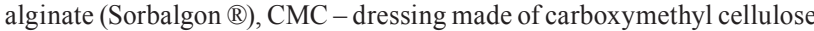
sodium salt (Aquacel ${ }^{\circledR}$ ), DBC - dibutyrylchitin, $1 \mathrm{ml}$ of the cell suspension was applied at the dressings in each well.

The wells in a 6-well plate was filled with $7 \mathrm{ml}$ complete culture medium: DMEM, 10\% FCS, $1 \% \mathrm{P} / \mathrm{S}$.

For the next 14 days $0.5 \mathrm{ml}$ of the supernatant was collected from each well to a sterile Eppendorf tubes. The tubes were stored at $-80^{\circ} \mathrm{C}$ until the ELISA tests were performed.

Supernatant samples drawn within 14 days allowed the determination of the release profile of cytokine production by fibroblasts and the effect of tested materials on the process

\section{RESULTS AND DISCUSSION}

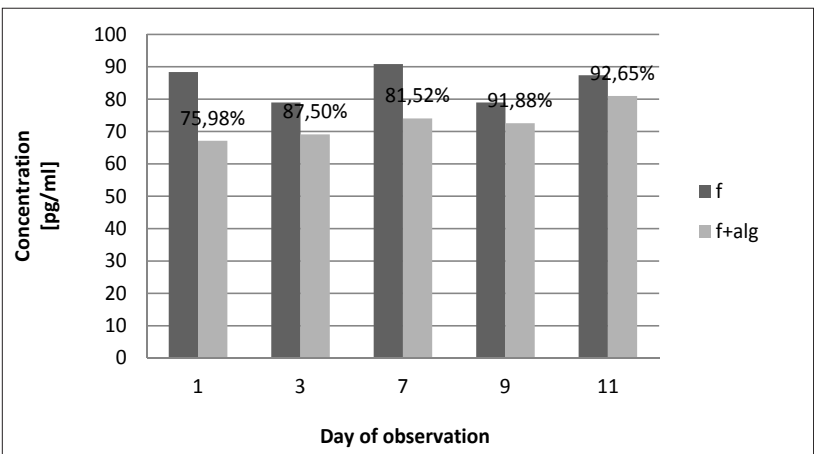

Figure 1. Graph of changes of IL-1 level secreted by the murine fibroblasts in contact with a dressing composed of calcium alginate

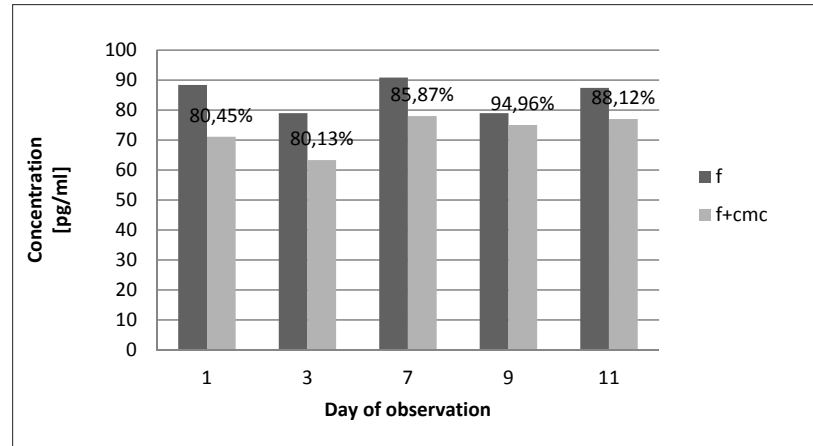

Figure 2. Graph of changes of IL-1 level secreted by the murine fibroblasts in contact with a dressing composed of sodium salt of carboxymethylcellulose

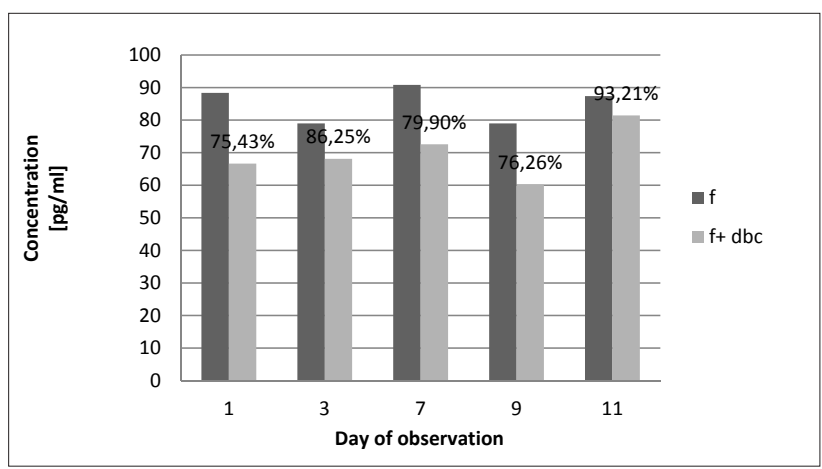

Figure 3. Graph of changes of IL-1 level secreted by the murine fibroblasts in contact with a dressing composed of dibutyrylchitn

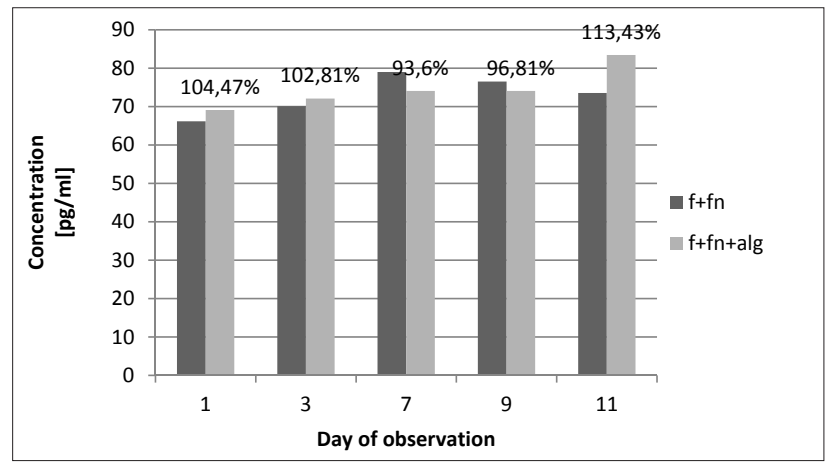

Figure 4. Graph of changes of IL-1 level secreted by the murine fibroblasts in contact with a dressing composed of calcium alginate (in the fibronectin presence)

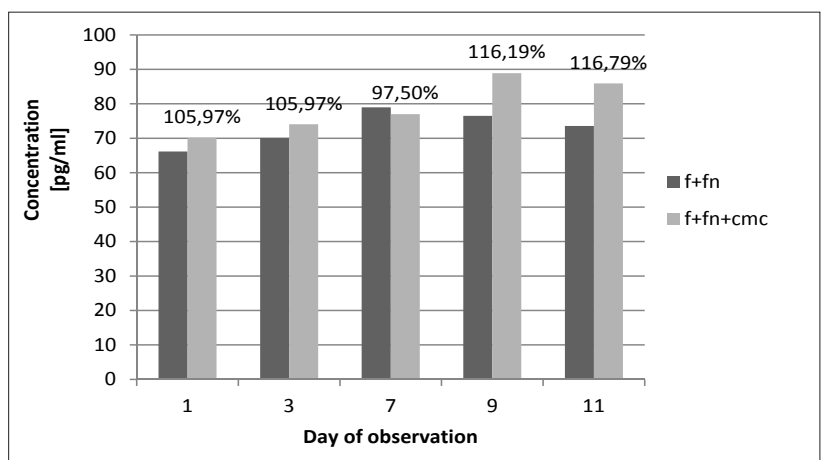

Figure 5. Graph of changes of IL-1 level secreted by the murine fibroblasts in contact with a dressing composed of sodium salt of carboxymethylcellulose (in the fibronectin presence) 


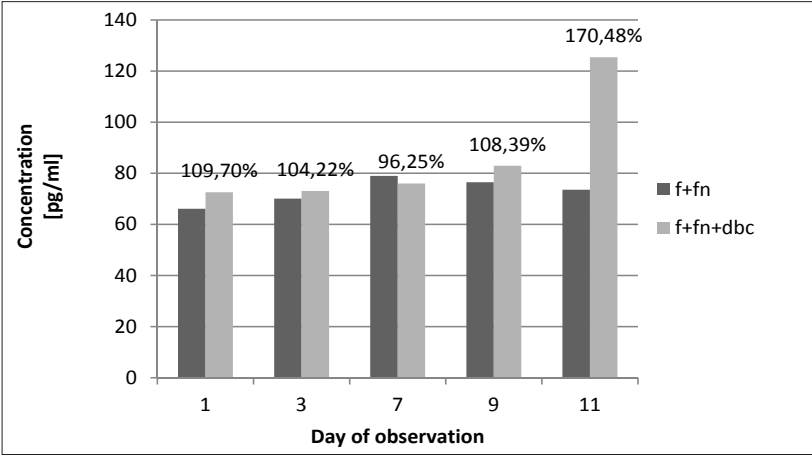

Figure 6. Graph of changes of IL-1 level secreted by the murine fibroblasts in contact with a dressing composed of dibutyrylchitn (in the fibronectin presence)

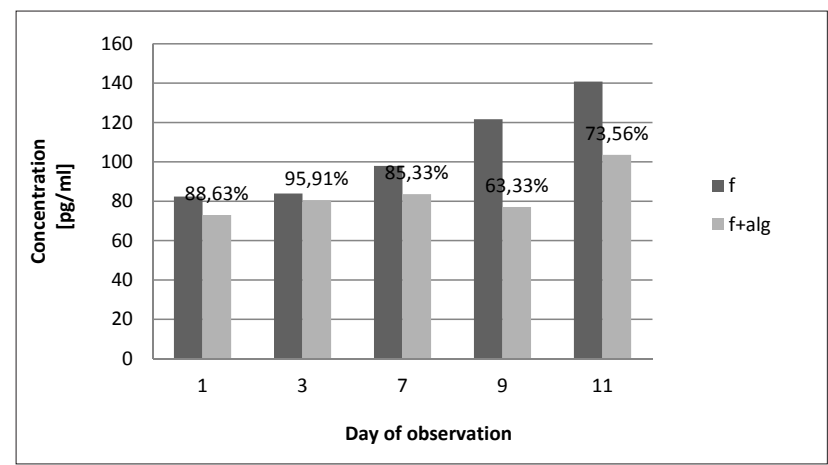

Figure 7. Graph of changes of IL-6 level secreted by the murine fibroblasts in contact with a dressing composed of calcium alginate

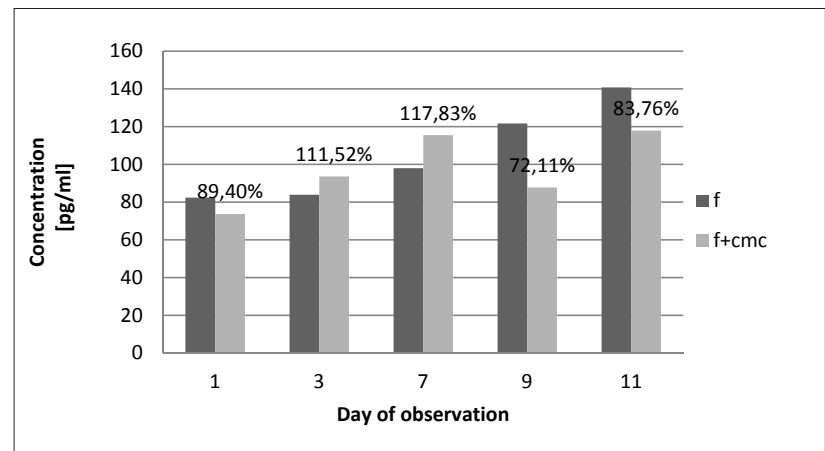

Figure 8. Graph of changes of IL-6 level secreted by the murine fibroblasts in contact with a dressing composed of sodium salt of carboxymethylcellulose

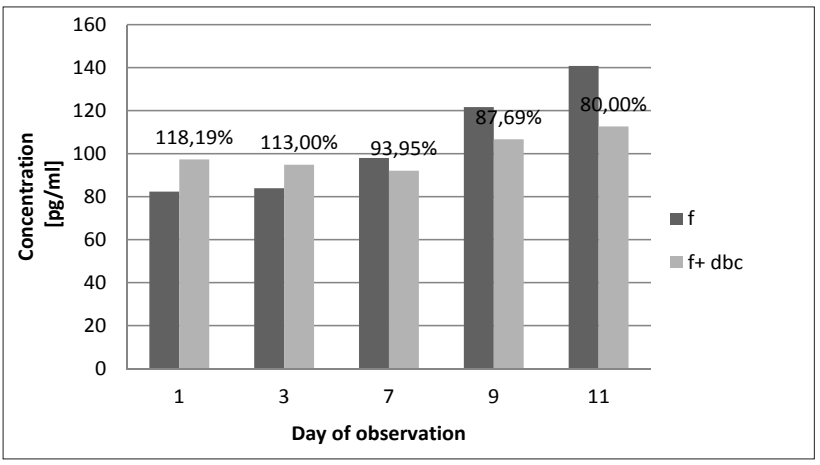

Figure 9. Graph of changes of IL-6 level secreted by the murine fibroblasts in contact with a dressing composed of dibutyrylchitn

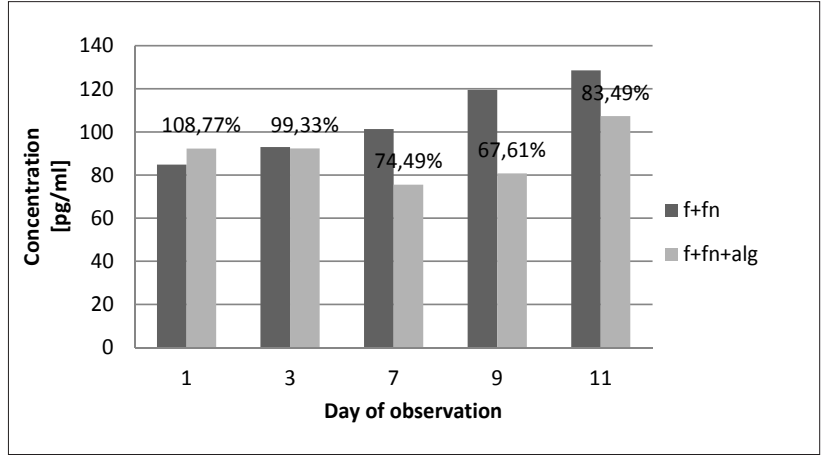

Figure 10. Graph of changes of IL-6 level secreted by the murine fibroblasts in contact with a dressing composed of calcium alginate (in the fibronectin presence)

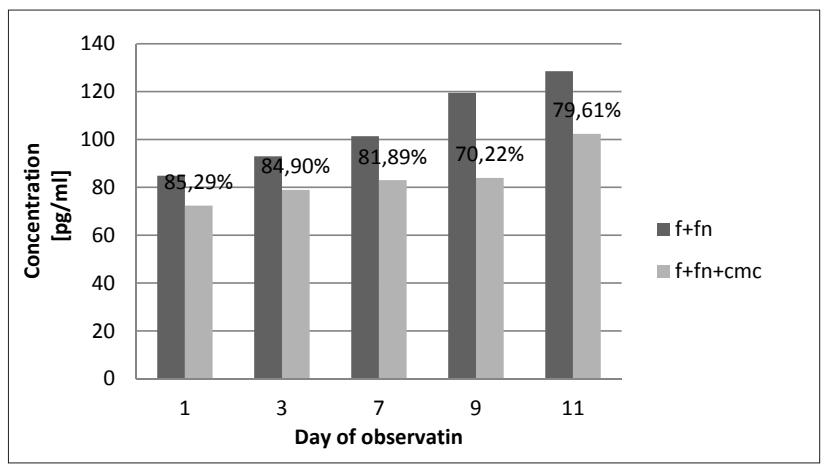

Figure 11. Graph of changes of IL-6 level secreted by the murine fibroblasts in contact with a dressing composed of sodium salt of carboxymethylcellulose (in the fibronectin presence)

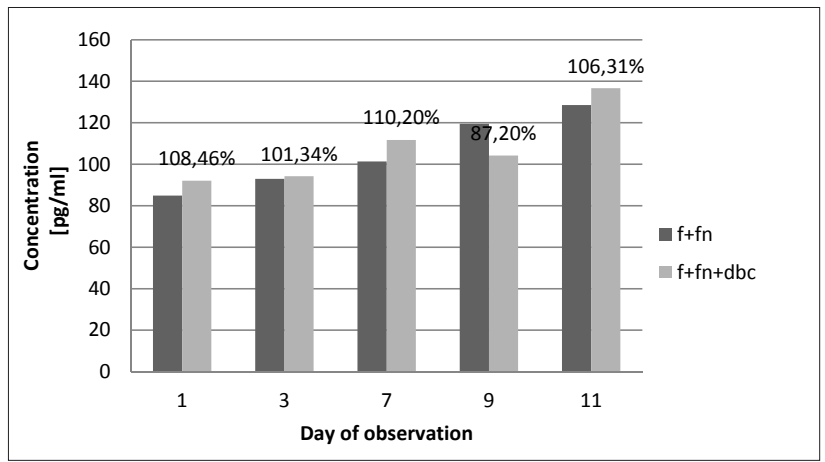

Figure 12. Graph of changes of IL-6 level secreted by the murine fibroblasts in contact with a dressing composed of dibutyrylchitn (in the fibronectin presence)

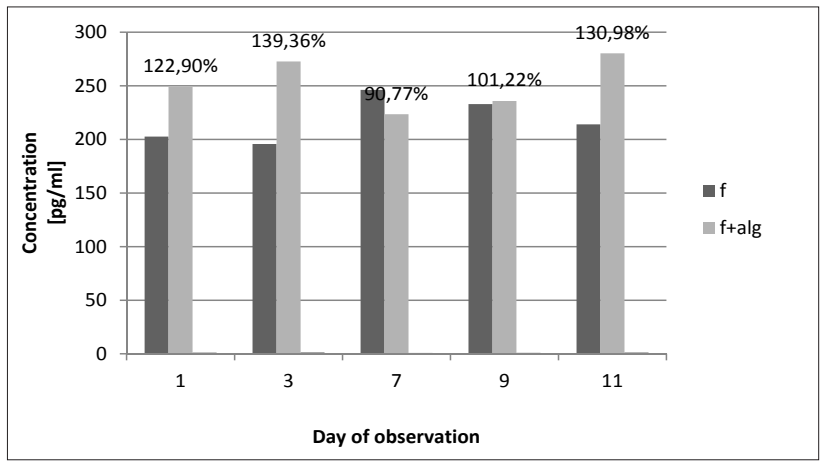

Figure 13. Graph of changes of IL-10 level secreted by the murine fibroblasts in contact with a dressing composed of calcium alginate 


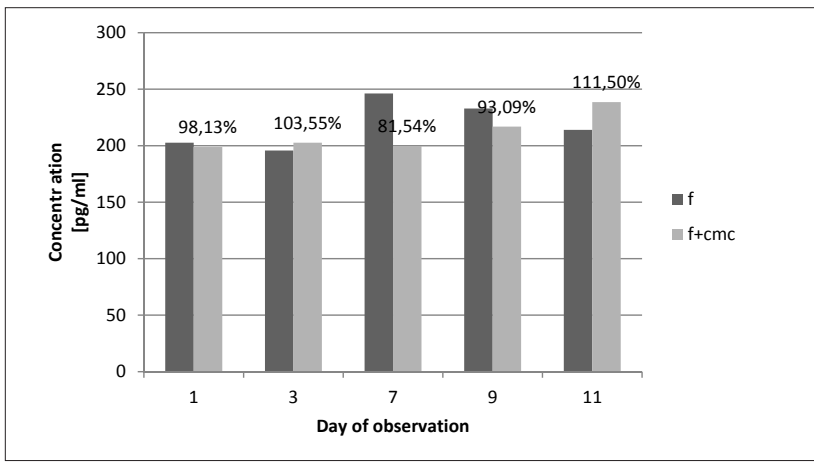

Figure 14. Graph of changes of IL-10 level secreted by the murine fibroblasts in contact with a dressing composed of sodium salt of carboxymethylcellulose

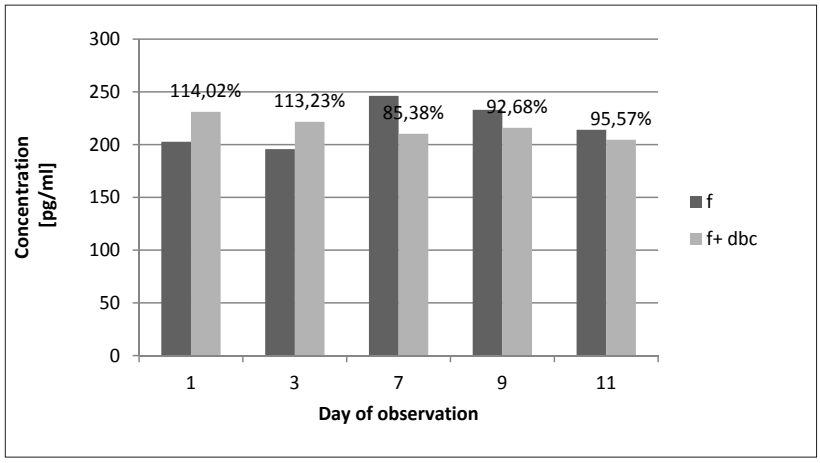

Figure 15. Graph of changes of IL-10 level secreted by the murine fibroblasts in contact with a dressing composed of dibutyrylchitin

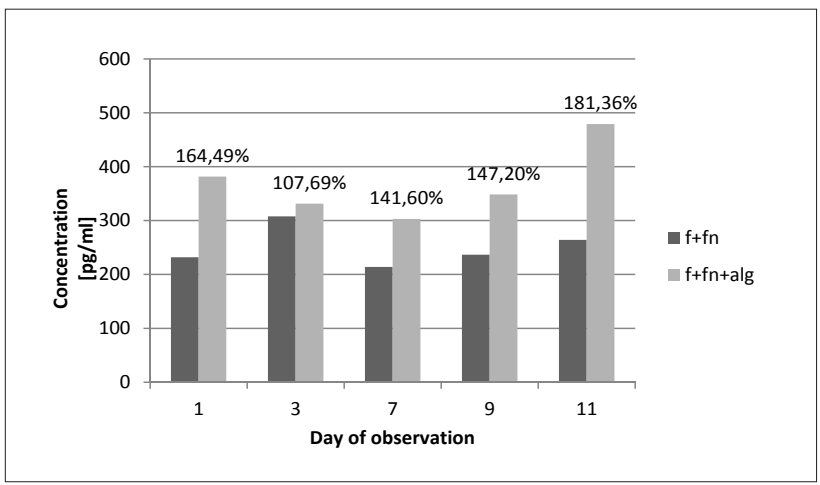

Figure 16. Graph of changes of IL-10 level secreted by the murine fibroblasts in contact with a dressing composed of calcium alginate (in the fibronectin presence)

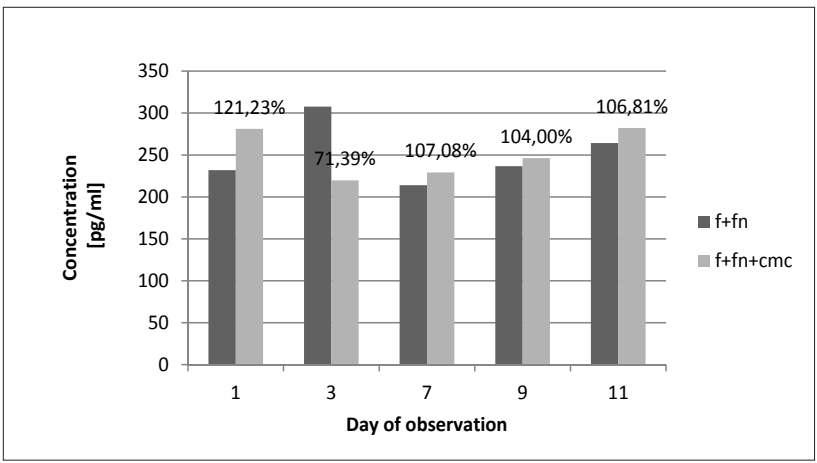

Figure 17. Graph of changes of IL-10 level secreted by the murine fibroblasts in contact with a dressing composed of sodium salt of carboxymethylcellulose (in the fibronectin presence)

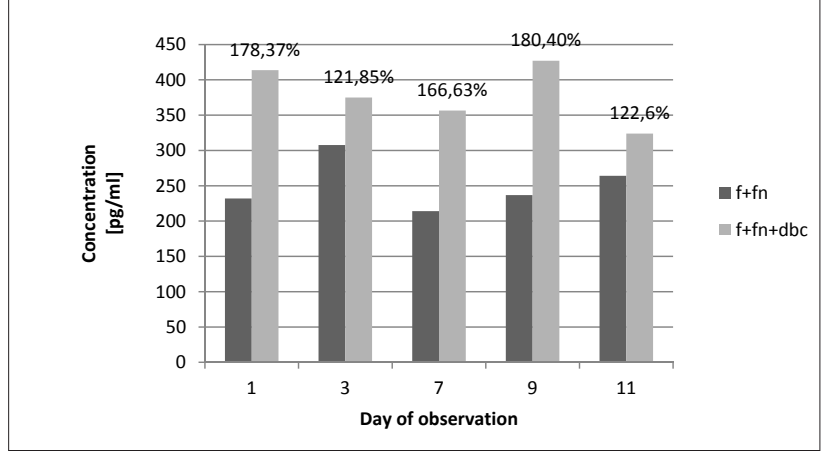

Figure 18. Graph of changes of IL-10 level secreted by the murine fibroblasts in contact with a dressing composed of dibutyrylchitin (in the fibronectin presence)

To determine the effect of the used polymers on the immune response in the fibroblasts cell lines several experiments were conducted.

We considered ELISA tests to evaluate the degree of secretions of interleukins crucial for wound healing process.

The results have show that the presence of the tested dressings induced inhibition of IL-1 by murine fibroblasts compared to the controls (Figure 1, Figure 2, Figure 3). This points to the influence of the tested biomaterials for the induction of the inflammatory response $[2,8]$.

Covering 6-well plates with fibronectin resulted in an increase secretion of pro-inflammatory interleukins IL-1 by fibroblasts seeded in contact with dressings. This observation was particularly evident in the $9^{\text {th }}$ and $11^{\text {th }}$ day of the experiment (Figure 4, Figure 5, Figure 6), which confirms the modulating effect of fibronectin at inflammatory process [30].

The dressing made with calcium alginate inhibits the secretion of pro-inflammatory interleukins IL-6 compared to the controls (Figure 7).

Dressings made with carboxymethylcellulose, and dibutyrylchitin resulted in an increase of the secretion of IL-6 in the first days of the experiment compared to the controls (Figure 8, Figure 9).

The addition of fibronectin in contact with a dressing composed of dibutyrylchitin caused an increase in concentrations of IL- 6 and a decrease in IL- 6 induced by contact with the carboxymethyl cellulose in relation to the controls which also confirms the modulating effect of fibronectin at inflammatory process [30].

The concentration of IL- 6 produced by mouse fibroblasts grown on first day experiment in contact with a dressing composed of calcium alginate coated on fibronectin coated plate (Figure 10).

Interleukin 1 (IL 1), interleukin 6 (IL 6) are typical examples of multifunctional cytokines involved in the regulation of the immune response, and inflammation. Their functions are crucial and widely overlapping $[9,28]$.

Addition of fibronectin increased the secretion of antiinflammatory interleukin IL-10 by murine fibroblasts upon the contact with dressing constructed from calcium alginate, carboxymethylcellulose, and dibutyrylchitin relative to controls (Figure 16, Figure 17, Figure 18) [30]. 
In the absence of fibronectin, secretion of IL-10 also increases in particular under the influence of calcium alginate (Figure 13), in relation to the dressing constructed of carboxymethylcellulose effect was strongest in the $11^{\text {th }}$ day of the experiment (Figure 14) and for dibutyrylchitin in day of $1^{\text {st }}$ and $3^{\text {rd }}$ (Figure 15 ).

The experiments suggest anti-inflammatory nature of tested dressings. Dressings made of calcium alginate, carboxymethylcellulose, and dibutyrylchitin cause inhibition of secretion of pro-inflammatory interleukin (IL-1, IL-6). This effect was diminished with previous coverage of tissue culture plates with fibronectin. The level of secretion of an anti-inflammatory interleukin IL-10 was the greatest when calcium alginate films were used as the substrate.

Inflammation is necessary for the proper conduction of the tissue healing and inhibition of this process may impair the proper granulation and epithelialization. These results suggest that the inflammatory process is silenced upon the contact with tested dressings.

The results of the experiments suggest the modulating effect of fibronectin on the secretion of immunologically active cytokines.

Our experiments suggest new lines of research that can contribute in the future design of the dressings inducing desired immunological effect.

The results will be further transferred to the next stage of in vivo experiments.

\section{REFERENCES}

1. Andersen T., et al.; Alginates as biomaterials in tissue engineering, Carbohydr. Chem., 37, 2012

2. Anderson J.M.; Biological responses to materials, Annu. Rev. Mater. Res. 31, 2001

3. Barnett S., Varley S.; The effects of calcium alginate on wound healing, Ann R Coll Surg Engl., 69, 4, 1987

4. Barrientos S., et al.; Growth factors and cytokines in wound healing, Wound Repair Regen. 16, 5, 2008

5. Burrow T., Welch M.J.; The development and use of alginate fibres in nonwovens for medical end-uses. In: Cusick GE, ed. Nonwoven Conference Papers, UMIST 1983

6. Eberlein T., et al; Comparison of PHMB-containing dressing and silver dressings in patients with critically colonised or locally infected wounds, J Wound Care, 21, 1, 2012.

7. Eming SA., et al.; Accelerated wound closure in mice deficient for interleukin-10, J.Pathol. 170.1, 2007.

8. Gallin J. I., et al.; Inflammation: Basic Principles and Clinical Correlates, New York Raven, $19992^{\text {nd }} \mathrm{ed}$.

9. Gallucci RM., et al; Interleukin-6 treatment augments cutaneous wound healing in immunosuppressed mice, J Interferon Cytokine Res., 21, 8, 2001.

10. Iannuccelli V., et al; Biodegradable intraoperative system for bone infection treatment II. In vivo evaluation. Int J Pharm, 143, 1996.

11. Ishikawa $\mathrm{K}$ et al; Self-setting barrier membrane for guided tissue regeneration method: initial evaluation of alginate membrane made with sodium alginate and calcium chloride aqueous solutions. J Biomed Mater Res., 47, 1999.
12. Jones V., Harding K.; Chronic Wound Care: A Clinical Source Book for Healthcare Professionals, 245-251, 2001

13. Kaneda K, Kuroda S, Goto N, Sato D, Ohya K, Kasugai S. ; Is sodium alginate an alternative haemostatic material in the tooth extraction socket?, J Oral Tissue Engin; 5, 2008

14. Krucinska I., et al.; Dibutyrylchitin nonwoven biomaterials manufactured directly from polymer solution. International Conference FiberMed06 - Fibrous Products in Medical and Health Care, Tampere, Finland, 2006

15. Krucińska I., et al.; Producing Wound Dressing Materials from Chitin Derivatives by Forming Nonwovens Directly from Polymer Solution, Fibres \& Textiles in Eastern Europe, 15, 5-6, 2007

16. Krucińska I., et al..; Biological Estimation of Dibutyrylchitin Nonwovens Manufactured by the Spraying of Polymer Solution Technique, in Progress on Chemistry and Application of Chitin and its Derivative, Polish Chitin Society, Polish Chitin Society, Monograph XI, 2006

17. Krzyżanowska-Gołąb D., Lemańska-PerekA., Kątnik-Prastowska I.; Fibronektyna jako aktywny składnik macierzy pozakomórkowej, Postepy Hig Med. Dosw. (online), 61, 2007

18. Labler L .et.al.; Vacuum-assisted closure therapy increases local interleukin-8 and vascular endothelial growth factor levels in traumatic wounds, J Trauma., 66,3,2009.

19. Mano J.et al.; Natural origin biodegradable systems in tissue engineering and regenerative medicine: present status and some moving trends, J R Soc. Interface. 22, 4, 2007

20. Matthew IR.et al; Subperiosteal,behavior of alginate and cellulose wound dressing materials. Biomaterials, 16, 4, 1995

21. Muzzarelli R.A. et al.; The biocompatibility of dibutyrylchitin in the context of wound dressings. Biomaterials, 26, 29, 2005

22. Pielka S. et al.; Healing acceleration by a textile dressings containing dibutyrylchitin and chitin. Fibres \& Textiles in Eastern Europe, 2, 41, 2003.

23. Pluta J., Haznar D.; Właściwości fizykochemiczne oraz kinetyka uwalniania substancji leczniczej z matryc żelatynowo-alginianowych, Polimery w Medycynie, 36, 3, 2006.

24. Schoukens G., Kiekens P., Krucińska I.; New bioactive textile dressing materials from dibutyrylchitin, Intern. J. of Clothing Science and Technology, 21, 2-3, 2009

25. Szewczyk M. et al.: Zasady wyboru opatrunków hydrofiber i alginianowych w leczeniu owrzodzeń żylnych, Zakażenia, 6, 2004

26. Szosland et al.; Opatrunki z dibutyrylochityny i chityny wspomagające gojenie się ran, IV Międzynarodowa Konferencja Naukowa Medtex 2002, Łódź.

27. Szosland L., Janowska G.; Patent PL No 169077 B1, 1996

28. Thomay A.A. et al.; Disruption of Interleukin-1 Signaling Improves the Quality of Wound Healing, J Pathol. 174, 6, 2009.

29. Turner T. D.; The development of wound management products, Wounds, 3, 1989.

30. Vercellotti G. M. et al.; Inflamed Fibronectin: An Altered Fibronectin Enhances Neutrophil Adhesion, Blood, 62, 5, 1983

31. Wang L., et al.;Evaluation of sodium alginate for bone marrow cell tissue engineering, Biomaterials, 24, 20, 2003

32. Winter G.D.; Formation of the Scab and the Rate of Epithelization of Superficial Wounds in the Skin of the Young Domestic Pig, Nature, 193,1962

33. Wu S. F. et al; Repair of facial nerve with alginate sponge without suturing: an experimental study in cats. Scand J Plast. Reconstr. Surg. Hand Surg., 36, 3, 2002. 